\title{
HPV-16E6 can induce multiple site phosphorylation of p53
}

\author{
GE ZHANG ${ }^{1,2}$, LINA SUN ${ }^{3,4}$, ZONGFANG LI ${ }^{1}$, LUSHENG SI ${ }^{4}$, TUSHENG SONG ${ }^{4}$, \\ CHEN HUANG ${ }^{4}$ and WANGGANG ZHANG ${ }^{1}$
}

\author{
${ }^{1}$ The Secondary Affiliated Hospital of School of Medicine, Xi'an; ${ }^{2}$ The First Hospital of Shanxi Medical University, Taiyuan; \\ ${ }^{3}$ State Key Laboratory for Infectious Disease Prevention and Control, National Institute for Infectious Disease Control and \\ Prevention, Chinese Centre for Disease Control and Prevention, Beijing; ${ }^{4}$ Key Laboratory of Environment and Genes \\ Related to Disease of the Education Ministry, School of Medicine, Xi'an Jiaotong University, Xi'an 710061, P.R. China
}

Received June 23, 2008; Accepted August 5, 2008

DOI: 10.3892/or_00000232

\begin{abstract}
Modulation of the activity of tumor suppressor p53 is a key event in the replication of many viruses. They could manipulate p53 function through modification of phosphorylation for their own purpose. However, there are scarce data on the relationship between high risk human papillomavirus (HPV) E6 protein and p53 phosphorylation status. Therefore, we used a mammalian green fluorescence protein (GFP) expression system to express HPV-16E6 with GFP fusion proteins in wild-type p53 cell lines, 293T, MCF-7, and SMMC-7721 to trace the traffic and subcellular location of E6 protein. By immunoblotting, we determined the positive phosphorylated sites of p53 in the context of HPV-16E6. Using immunofluorescence techniques, we observed the distribution of phosphorylated p53 in all the cells we used. In conclusion, HPV-16E6 was predominantly located in nuclei of wild-type p53 cells, and it was able to induce phosphorylation of p53 at multiple sites, such as $\operatorname{Ser}^{15}, \operatorname{Ser}^{20}$, and $\mathrm{Ser}^{392}$. The level and time of these phosphorylated sites of p53 were different in HPV-16E6 expressing cells. Furthermore, the phosphorylated p53 was localized in the nuclei together with HPV-16E6.
\end{abstract}

\section{Introduction}

Human papillomaviruses (HPVs) are small double-stranded DNA viruses with a genome of $\sim 8 \mathrm{~kb}$ (1). They can infect

Correspondence to: Dr Chen Huang, Key Laboratory of Environment and Genes Related to Diseases of the Education Ministry, Department of Genetics and Molecule Biology, School of Medicine, Xi'an Jiaotong University, Xi'an 710061, P.R. China E-mail: hc.xjtu@yahoo.com

Dr Wanggang Zhang, The Second Affiliated Hospital of School of Medicine, Xi'an Jiaotong University, Xi'an 710061, P.R. China E-mail: zhangwanggang@yahoo.com

Key words: human papillomavirus, E6, p53, phosphorylation keratinocytes in the basal layer of stratified epithelia at a variety of anatomical sites (2). On the basis of their tissue tropism, the HPVs can be subdivided into cutaneous and mucosal types, which infect the skin and the mucosa, respectively (3). Over $90 \%$ of human cervical carcinoma is associated with high risk mucosal HPVs, mainly the serotypes 16 and 18 (4). The mechanisms underlying the actions of high risk HPVs leading to cancer have been studied extensively, and it was shown that the E6 and E7 proteins were the oncoproteins interacting with tumor suppressors p53 and pRB, respectively, and leading to infected-cell transformation and dysregulated proliferation (5). Previous studies also showed that the principle activity of E6 was to target and degrade p53, therefore, the p53 growth regulatory function is abolished (6). However, research has demonstrated that a substantial proportion of HPV positive cervical carcinomas are also p53 positive $(7,8)$. There might be other ways for E6 interaction with p53.

The tumor suppressor protein p53 regulates cell cycle progression and cell survival in response to a wide range of cellular stresses, such as oncogenic activation, hypoxia, DNA damage, or viral infection (9-11). Following activation, p53 coordinates a change in the balance gene expression leading to growth or survival of damaged cells (12). Activation of p53 also can be modulated as translocation of p53 to nucleus where it acts as a transcriptional factor, and post-translational modification. The post-translational modification of p53 is regulated by phosphorylation, acetylation, sumoylation and ubiquitination events that contribute to the conversion of $\mathrm{p} 53$ from a latent to an active transcription factor $(13,14)$.

Phosphorylation of p53 has been studied most intensely and has been proposed to play a critical role in the stabilization and activation of p53 (15). At least 20 sites in the human p53 located primarily in the $\mathrm{N}$-terminal transactivation domains or in the C-terminal regulatory domain are modified in response to the activation of different stress signaling pathways (16). For example, phosphorylation of p53 at N-terminal serines (serines 6, 9, 15, 20, 33 and 37) may enhance interactions with the transcriptional co-activators p300/CBP and PCAF. Additionally, phosphorylation of $\mathrm{Ser}^{15}, \mathrm{Ser}^{20}$, and $\mathrm{Ser}^{37}$ were reported to stabilize $\mathrm{p} 53$. At the $\mathrm{C}$ terminus, phosphorylation of $\mathrm{Ser}^{315}$ and $\mathrm{Ser}^{392}$ were implicated in regulating the oligomerization state of p53 and its ability to bind DNA in a 
sequence-specific manner (16-18). Previous studies have also examined the effects of several phosphorylated sites within p53 on the biological activity of the protein by different DNA damage stress (19). Of the multiple sites within $\mathrm{p} 53, \operatorname{Ser}^{15}$ is the first site shown to be inducibly phosphorylated. DNAdependent PK and the ATM protein are capable of phosphorylating serine 15 in response to DNA damage, particularly after IR, and thereby inhibiting the ability of $\mathrm{mdm}-2$, the primary negative regulator of $\mathrm{p} 53$, to complex with $\mathrm{p} 53$ and target it for degradation (20). Similarly, the phosphorylation of serine 20 is believed to be involved in the dissociation of p53 from mdm-2 and to mediate the p53 response to IR (21). In contrast, serine 392 in the $\mathrm{COOH}$ terminus is shown to be phosphorylated by casein kinase II and to mediated response to UV but not $\gamma$-radiation (22). Thus current evidence suggests that phosphorylation of p53 may play a role in regulating p53 functions in response to DNA damage stresses. On the other hand, viral replication is also recognized as DNA damage stresses by infected cells, and it is tightly associated with p53 phosphorylation (23). For example, Epstein-Barr virus (EBV), Africa swine fever virus (ASFV), and Kaposi's sarcoma associated herpesvirus (KSHV), can manipulate p53 for its own purpose with the different phosphorylated p53 in infected cells (23-25). However, there are scarce data on p53 phosphorylation status in the context of HPV-E6.

In the present study, we investigated whether the oncogene E6 of HPVs could induce phosphorylation of p53. Previous studies have shown most of the human cancers in which p53 is mutated, whereas in cervical carcinoma and derived cell lines, the p53 is rarely mutated. Therefore, we chose 293T, MCF-7, and SMMC-7721 cells, which were wild-type p53 cell lines. We used a mammalian GFP expression system to express full-length HPV-16E6 with GFP fusion protein in these three wild-type p53 cell lines. By confocal microscopy, we observed the HPV-16E6 was mainly located in the nuclei. The detail data of subcellular localization of HPV-16E6 showed there were more HPV16E6s entering to nuclei along with the time course. We next used immunoblotting to screen the positive phosphorylated p53 sites induced by HPV-16E6 within multiple important sites, such as $\mathrm{Ser}^{6}, \mathrm{Ser}^{9}, \mathrm{Ser}^{15}, \mathrm{Ser}^{20}, \mathrm{Ser}^{37}, \mathrm{Ser}^{46}$, and $\mathrm{Ser}^{392}$. By immunofluorescence technique, we further investigated the subcellular location and expression level of phosphorylated p53 from 12 to $72 \mathrm{~h}$. In conclusion, for the first time, we observed in the context of HPV-16E6, that there were three phosphorylated sites of p53, including Ser ${ }^{15}$, $\operatorname{Ser}^{20}$ and $\operatorname{Ser}^{392}$. Furthermore, the phosphorylated p53s and HPV-16E6 were co-localized in the nuclei of cells we used.

\section{Materials and methods}

Construction of expression vector. Full length HPV-16E6 sequence was amplified by PCR from HPV type 16 complete genome, and then cloned in frame within the $\mathrm{C}$ terminus of EGFP at the $B g l \mathrm{II}$ and EcoRI sites of the polylinker regions of the mammalian expression vector pEGFP-C1 (Clontech, Palo Alto, CA), producing plasmid pGFP-16E6.

Cell culture and transfection. The human breast adenocarcinoma human embryonic 293T kidney cells, MCF-7 cells, and human hepatic cancer SMMC-7721 cells were maintained in RPMI-1640 medium (Gibco) supplemented with $10 \%$ fetal bovine serum (FBS) at $37^{\circ} \mathrm{C}$ in a humidified atmosphere of $5 \% \mathrm{CO}_{2}$. Cells were seeded on glass coverslips in 12-well cell culture plates. The cells were transiently transfected with plasmid pGFP-16E6, pGFP overnight using Lipofectamine 2000 transfection reagent (Invitrogen, Carlsbad, CA).

Cell imaging by confocal microscopy. The 293T, MCF-7, and SMMC-7721 cells were grown on glass coverslips, transfected, and at $21 \mathrm{~h}$ post-transfection were fixed with $4 \%$ paraformaldehyde for $10 \mathrm{~min}$ at room temperature. They were then rehydrated 3 times with cold phosphate buffered saline (PBS), stained with PI (Propidium Iodide, $100 \mu \mathrm{g} / \mathrm{ml}$ ) at $37^{\circ} \mathrm{C}$ in the dark for $10 \mathrm{~min}$, rinsed again with PBS, and mounted on slides. Images of cells were collected with a Leica confocal microscope (Leica Microsystems, Wetzler, Germany) at a magnification of $x 400$. Fluorescent images were analyzed using a Leica Confocal Software (Leica Microsystems).

Immunoblotting analysis. For each sample, $10^{6}$ cells were collected by centrifugation (1000 x rpm for $5 \mathrm{~min}$ ), washed once with ice cold PBS, and lysed in $100 \mu 1 \mathrm{RIPA}$ buffer containing $50 \mathrm{mM}$ Tris- $\mathrm{HCl}(\mathrm{pH} 7.4), 150 \mathrm{mM} \mathrm{NaCl}, 1 \%$ NP-40, 0.5\% sodium deoxycholate, $1 \mathrm{mM}$ EDTA, $2.5 \mathrm{mM}$ glycerophosphate, $1 \mathrm{mM}$ PMSF, $10 \mathrm{mM} \mathrm{NaF}$, and protease inhibitors (Complete Mini, Roche Diagnostics, Mannheim Germany). Protein concentration was determined using the BCA reagents (Pierce, Rockford, IL). Samples (30 $\mu \mathrm{g})$ were analyzed on $12 \%$ SDS polyacrylamide gels, transferred to PVDF membranes (Invitrogen), and blocked for $1 \mathrm{~h}$ at room temperature with $5 \%$ non-fat milk in TBS buffer $[20 \mathrm{mM}$ Tris- $\mathrm{HCl}(\mathrm{pH} 7.5) 0.5 \mathrm{M} \mathrm{NaCl}]$. The membranes were then incubated with the primary antibody overnight at $4{ }^{\circ} \mathrm{C}$. After three washes with TBS, the membranes were incubated with the secondary antibody for $30 \mathrm{~min}$ at room temperature. After three additional washes, the proteins were visualized by enhanced chemiluminescence (ECL) (Amersham Pharmacia, Piscataway, NJ, USA).

The following primary antibodies were used: antiphospho-p53 Ser6, anti-phospho-p53 Ser9, anti-phospho-p53 Ser15, anti-phospho-p53 Ser20, anti-phospho-p53 Ser37, anti-phospho-p53 Ser46, and anti-phospho-p53 Ser 392 (Cell Signaling; dilution, 1:1,000).

Immunocytochemistry. The cells were seeded on glass coverslips at a density of $1-2 \times 10^{5}$ cells/well. Then, they were transfected with plasmid pGFP-16E6 and pGFP overnight following standard procedures. After transfection, the cells were washed with PBS and fixed with $4 \%$ paraformaldehyde for $10 \mathrm{~min}$ at room temperature. They were then rehydrated 3 times with cold PBS, permeabilized with $1 \%$ Triton X-100 for $5 \mathrm{~min}$ on ice, and rinsed with PBS and blocked. The cells were incubated with primary antibodies overnight at $4^{\circ} \mathrm{C}$. Subsequently, signal detection was performed using $\mathrm{Cy} 3-$ conjugated goat anti-rabbit IgG (Sigma; dilution, 1:200) in blocking solution for $30 \mathrm{~min}$ at room temperature in the dark. Then, the cells were washed 3 times with PBS and examined by confocal microscopy. 


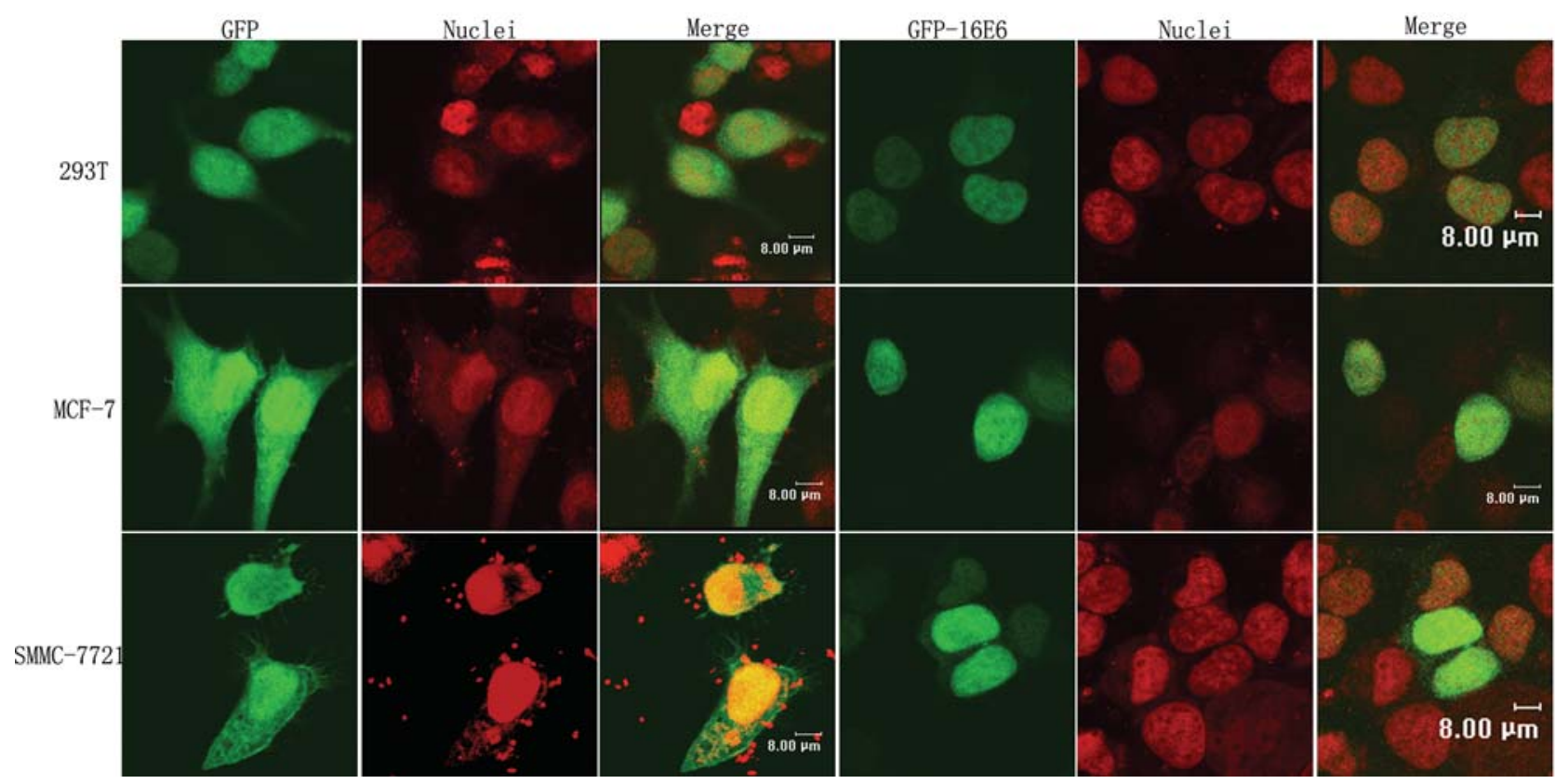

Figure 1. HPV-16E6 was predominantly located in nuclei. Representative photographs of 293T, MCF-7, and SMMC-7721 at $21 \mathrm{~h}$ after transfecting with GFP and GFP-16E6 expression plasmid. The green fluorescence is emitted by the cells transfected with pGFP and pGFP-16E6, respectively. The red is PI stained nuclei.
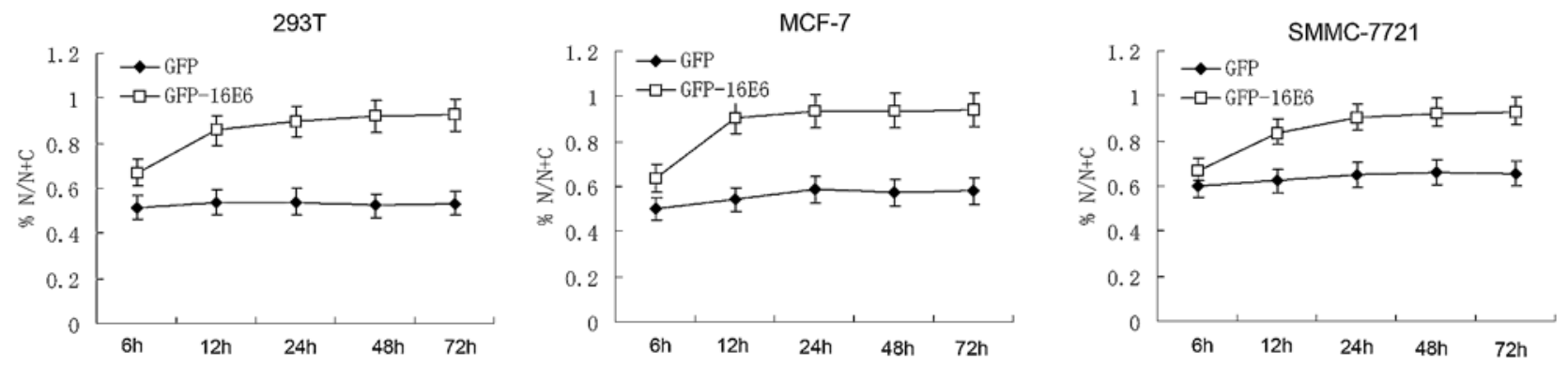

Figure 2. Nuclear signal of E6 was enhanced at later times of transfection. The data of fluorescence intensity ratio of GFP fusion protein in the nuclei versus in the nuclei and cytoplasm $(\mathrm{N} / \mathrm{N}+\mathrm{C})$ were examined by fluorescence intensity. One-hundred cells were examined for each plasmid from $20 \mathrm{x}$ random fields.

Statistics. All data were recorded as means \pm standard deviation, and analyzed by the SPSS 11.0 software. Analysis of data was performed using one-way ANOVA for multiple comparisons. $\mathrm{P}<0.05$ were considered statistically significant.

\section{Results}

HPV-16E6 was mainly located in the nuclei. Viral E6 coding regions were inserted within the $C$ terminus of the $\mathrm{pGFP}$ (vector pEGFP-C1), producing plasmid pGFP-16E6. The plasmid pGFP-16E6 was transiently transfected in 293T, MCF-7, and SMMC-7721 cells, allowing E6 proteins to be expressed as GFP-16E6 fusion proteins. By confocal microscopy, we observed the subcellular location of GFP$16 \mathrm{E} 6$ and GFP in three cell lines. The results indicated that GFP-16E6 protein was expressed essentially in the nuclei. As control, we observed the expression of GFP alone. It exhibited a diffused signal, and was present in the nuclei and cytoplasm (Fig. 1).
More E6 entering the nucleic along with time course. We further investigated the detail data of subcellular localization of HPV-16E6. We studied the fluorescence intensity ratio of GFP fusion protein in the nuclei versus in the nuclei and cytoplasm (N/N+C). For 293 T cells, E6 protein essentially located in the nuclei and its value of $\mathrm{N} / \mathrm{N}+\mathrm{C}$ increased gradually from 6 to $72 \mathrm{~h}$ post-transfection. As GFP control expressing $293 \mathrm{~T}$ cells, it was present in nuclei and cytoplasm, and its $\mathrm{N} / \mathrm{N}+\mathrm{C}$ was not changed. For MCF-7 and SMMC-7721 cells, the N/N+C of GFP-16E6 increased obviously from 6 to $12 \mathrm{~h}$ post-transfection $(\mathrm{P}<0.001)$, then it maintained at a high level from 12 to $72 \mathrm{~h}$. This indicated there were more E6 entering the nuclei from 6 to $12 \mathrm{~h}$. E6 stayed in the nuclei without being exported to the cytoplasm. As control, we observed the expression of GFP alone in MCF-7 and SMMC-7721 cells. It exhibited a diffused signal, and was present equally in the nucleus and cytoplasm. The $\mathrm{N} / \mathrm{N}+\mathrm{C}$ of GFP was not changed during the whole period (Fig. 2). Using confocal microscopy, we clearly observed 


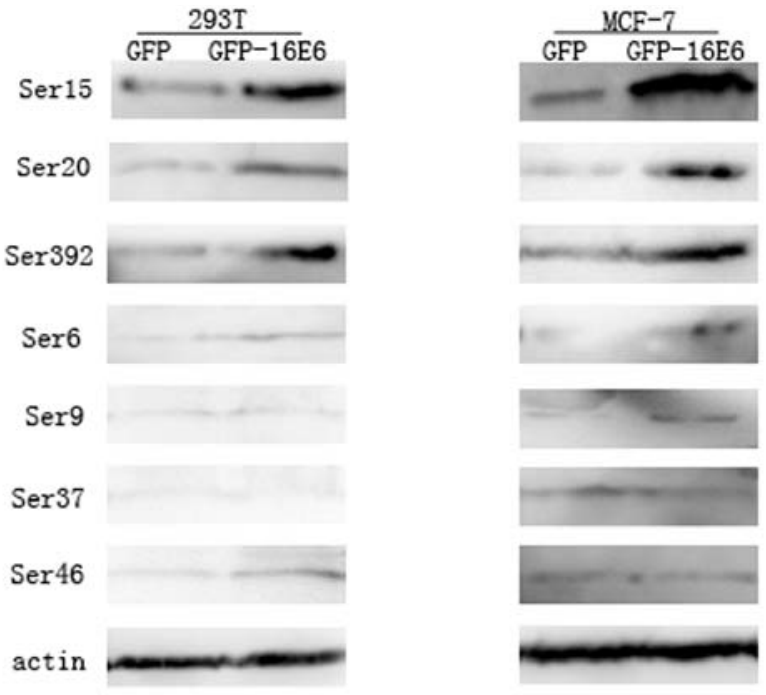

Figure 3. HPV-16E6 promotes multiple site phosphorylation of p53. The phosphorylated responses were obvious at three sites: $\mathrm{Ser}^{15}, \mathrm{Ser}^{20}$, and $\mathrm{Ser}^{392}$ of p53 in GFP-16E6 expressing 293T and MCF-7 cells. Data are normalized to $B$-actin and representive of three independent Western blot analyses.

that the nuclear signal of E6 was enhanced at later times of transfection.

HPV-16E6 promotes multiple site phosphorylation of p53. Since there were more HPV-16E6s entering the nuclei along with time course, we next determined whether the wild-type p53 was phosphorylated in transfected cells. We used antibodies for different sites that recognizing p53 only when it had been modified at these sites. By immunoblotting, we clearly observed phosphorylated p53 in GFP-16E6 expressing 293T and MCF-7 cells. The result indicated that the phosphorylated responses were obvious at three sites: $\mathrm{Ser}^{15}, \mathrm{Ser}^{20}$, and $\mathrm{Ser}^{392}$ of p53 in GFP-16E6 expressing 293T and MCF-7 cells. In GFP-16E6 expressing cells, the band for $\mathrm{Ser}^{6}, \mathrm{Ser}^{9}, \mathrm{Ser}^{37}$, and $\mathrm{Ser}^{46}$ sites of p53 was maintained at a very low level which was similar with GFP control cells respectively (Fig. 3).

Co-localization of HPV-16E6 and phosphorylated p53 proteins. Since high risk HPV-E6 can target and interact with p53 (26), we suspected that the HPV-16E6 and phosphorylated p53 may locate together. By immunocytochemistry staining, we observed phosphorylated p53 proteins at three sites, including $\operatorname{Ser}^{15}, \operatorname{Ser}^{20}$ and $\operatorname{Ser}^{392}$, which were all highly expressed in $293 \mathrm{~T}$ and MCF-7 cells. This was consistent with our results by immunoblotting analysis as noted above. Furthermore, we observed the phosphorylated p53 was located in the nuclei together with GFP-16E6. Fig. 4 shows representative photographs of the co-localization of GFP-16E6 and phosphorylated p53 proteins. In the GFP control expressing cells, there was no obvious phosphorylated p53 (data not shown). Taken together, the phosphorylated p53 was essentially located in the nuclei together with GFP-16E6.

Level of phosphorylated p53 in the context of HPV-16E6. Since the expression of GFP-16E6 was associated with time course, we next determined the phosphorylated p53 level in $293 \mathrm{~T}$ and MCF-7 cells at 12-72 h post-transfection. For GFP-16E6 expressing cells, the $\operatorname{Ser}^{15}, \operatorname{Ser}^{20}$ of p53 were firstly detected at $12 \mathrm{~h}$ post-transfection and increased gradually, and significant accumulation was observed at 48 and $72 \mathrm{~h}(\mathrm{P}<0.001)$. The expression level of $\mathrm{Ser}^{15}$ was higher than $\operatorname{Ser}^{20}$ at the same time point $(\mathrm{P}<0.001)$. It should be

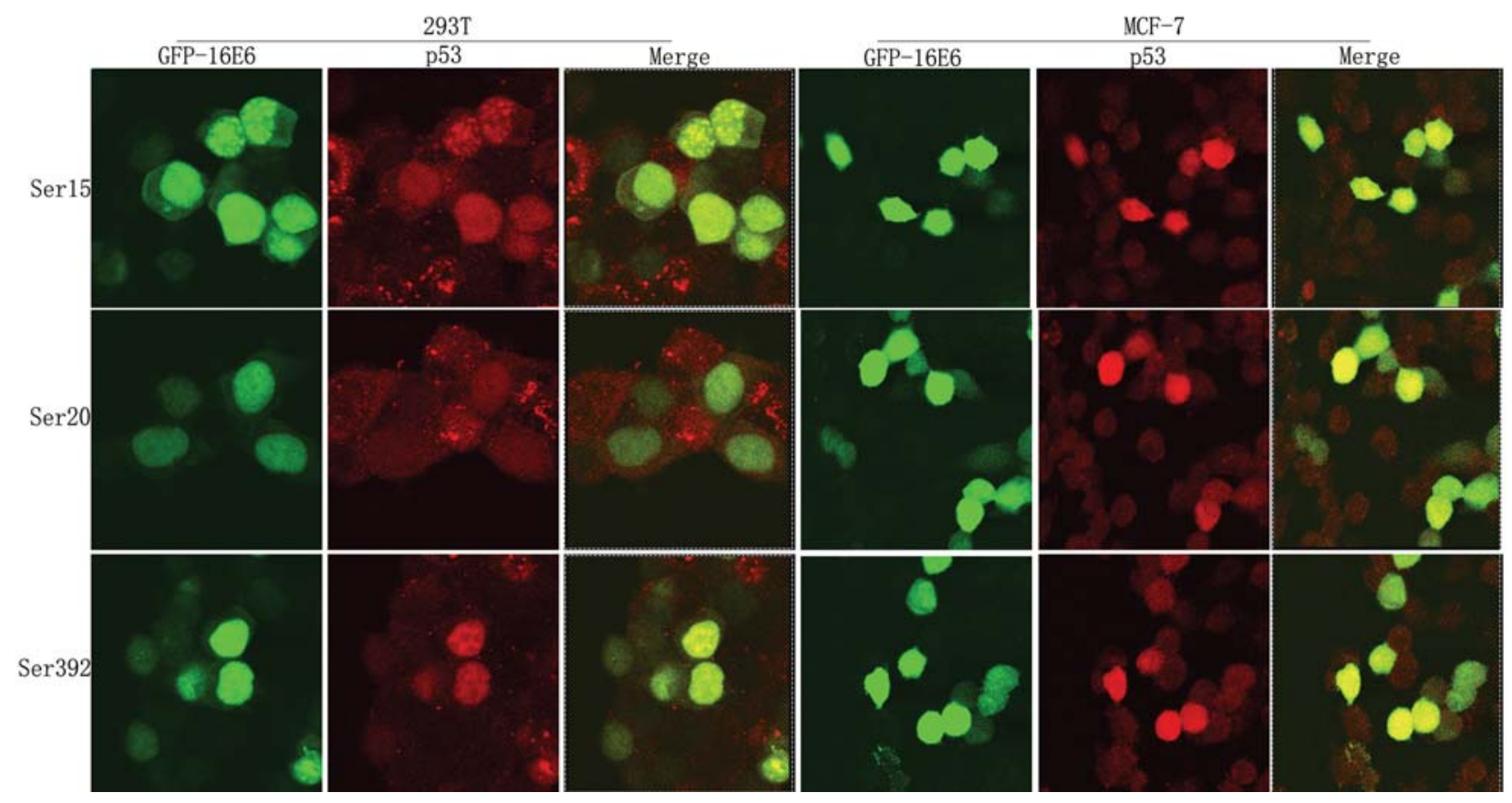

Figure 4. Co-localization of HPV-16E6 and phosphorylated p53 proteins. The phosphorylated p53 was located in nuclei together with GFP-16E6. Green fluorescence indicates the protein of GFP and GFP-16E6 expressed by the transfected cells. Red fluorescence indicates phosphorylated p53 proteins, which were labeled with phosphorylated anti-p53 antibodies plus anti-rabbit-Cy3 secondary antibody. The results shown are representative of three independent experiments. 

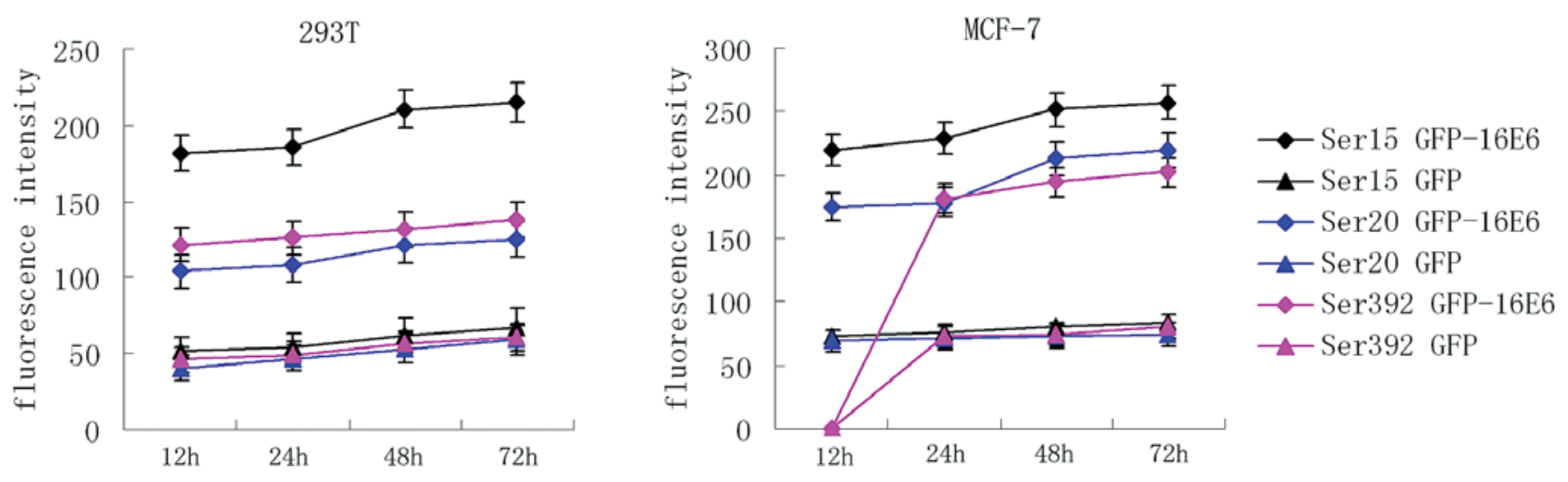

Figure 5. Level of phosphorylated p53 in the context of HPV-16E6 from 12 to $72 \mathrm{~h}$. The data of phosphorylated p53 level were examined by fluorescence intensity. One hundred cells were examined for each phosphorylated site of p53 from 20x random fields.

noted that phosphorylation of $\operatorname{Ser}^{392}$ was not present at $12 \mathrm{~h}$ in GFP-16E6 transfected MCF-7 cells, whereas it was highly expressed in GFP-16E6 transfected 293T at the same time. Then for the two cells, Ser ${ }^{392}$ increased gradually from 24 to $72 \mathrm{~h}$ post-transfection. As GFP control expressing cells, the phosphorylated p53 at $\mathrm{Ser}^{15}, \mathrm{Ser}^{20}$, and $\mathrm{Ser}^{392}$ maintained in very low levels during the whole period (Fig. 5). For Ser6, $\operatorname{Ser}^{9}, \operatorname{Ser}^{37}$ and $\operatorname{Ser}^{46}$, they appeared to be constitutively phosphorylated at a relatively low level in the treatment of GFP-16E6, which were similar to GFP control cells (data not shown).

Taken together, we observed obvious phosphorylation in $\mathrm{Ser}^{15}, \mathrm{Ser}^{20}$, and $\mathrm{Ser}^{392}$ of p53 induced by E6. However, the time and level of phosphorylated p53 proteins were different in $293 \mathrm{~T}$ and MCF-7 cells.

\section{Discussion}

In this study, we used a mammalian GFP expression system to express full-length 16E6 protein in wild-type p53 cell lines, to determine the p53 phosphorylation status in the context of HPV-16E6. We concluded that the HPV-16E6 was a nuclear protein and there were more 16E6 entering the nuclei along with the time course. HPV-16E6 induced multiple site phosphorylation of $\mathrm{p} 53$, and the phosphorylated p53s were located in nuclei together with HPV-16E6.

Infected cells recognize viral replication as a DNA damage stress and elicit the host surveillance mechanism to anti-virus infection. The modulation of p53 function by phosphorylation seems to be a major antiviral defense mechanism employed by cells. Regulation of p53 phosphorylation has been shown to be induced by many viruses, such as, Africa swine fever virus (ASFV), the p53 in host cell is stabilized by phosphorylation at $\operatorname{Ser}^{392}$ and is located in the nucleus. During infection, the phosphorylated p53 is functionally active inducing apoptosis along with the expression of p21 and mdm2 (25). The Epstein-Barr virus (EBV) can activate p53 through phosphorylated modification at $\mathrm{Ser}^{15}, \mathrm{Ser}^{20}$, and $\mathrm{Ser}^{392}$ modulated by its oncogenic protein LMP1. Additionally, the phosphorylated p53s were associated with MAPK kinases and the activation of MAPK kinases could target the transcription factors to anti-virus infection (24). On the other hand, some viruses have evolved strategies such as reducing the phosphorylation of p53 for counteraction p53 activation. For example, Kaposi's sarcoma associated herpesvirus (KSHV) is associated with the pathogenesis of Kaposi's sarcoma, KSHV viral interferon regulatory factor 1 (vIRF1) greatly reduced the level of serine 15 phosphorylation of p53, resulting in an increase of p53 ubiquitination and thereby a decrease of its protein stability which could circumvent host growth surveillance and facilitate viral replication in infected cells (23). However, there is a lack of studies on HPV-E6 protein and p53 phosphorylation.

In the present study, we constructed a transient HPV16E6 expressing system, and we observed HPV-16E6 was a nucleic protein. Additionally, there were more E6 entering the nuclei along with the time course. Phosphorylation of p53 was one of the major defense mechanisms against viral infection. Therefore, we studied p53 phosphorylation in the context of overexpressed E6. Interestingly, we found that p53 could be phosphorylated clearly at $\mathrm{Ser}^{15}, \mathrm{Ser}^{20}$, and $\mathrm{Ser}^{392}$, and the phosphorylated p53 were all located in the nuclei. The result suggested E6 can induce phosphorylation of p53 at multiple sites. Phosphorylation of $\mathrm{p} 53$ at $\mathrm{Ser}^{15}$ and $\mathrm{Ser}^{20}$ were the earliest response to E6 expression. It is generally believed that Ser ${ }^{15}$ phosphorylation of p53 occurs rapidly in response to DNA damage and appears to represent a 'priming event' for the subsequent series of modifications (27). Since phosphorylation of $\operatorname{Ser}^{15}$ induced by ATM/ATR results in dissociation of p53 from its negative regulator mdm-2, it has been suggested that the primary effect of phosphorylation of p53 at $\operatorname{Ser}^{15}$ is to increase p53 level $(28,29)$. The $\operatorname{Ser}^{20}$ is also critical for stabilizing of $\mathrm{p} 53$. Recent studies have demonstrated that $\operatorname{Ser}^{20}$ on p53 is phosphorylated by Chk1 or Chk2, enhancing its tetramerization, stability, and activity in response to DNA damage $(30,31)$. Phosphorylated sites at the $\operatorname{Ser}^{15}$ and $\operatorname{Ser}^{20}$ residues lie right under the binding pocket of mdm-2, which could disrupt the binding with mdm-2, resulting in the stabilization of p53 $(32,33)$. Furthermore, the phosphorylated p53 at $\operatorname{Ser}^{15}$ and $\mathrm{Ser}^{20}$ have been shown to play a role in $\mathrm{p} 53$-mediated apoptosis, this can be an important anti-virus response employed by cells. In the present study, the level of phos- 
phorylation of p53 at $\operatorname{Ser}^{15}$ was clearly higher than $\operatorname{Ser}^{20}$. For HPV-16E6, it is probably because $\operatorname{Ser}^{15}$ phosphorylation of p53 was the more important target than Ser $^{20}$. This was consistent with some data reported that removing Ser ${ }^{15}$ can abrogate phosphorylation at $\operatorname{Ser}^{20}(34)$. For phosphorylation of p53 at $\mathrm{Ser}^{392}$, it was not the same for the two cell types. In 293T cells, phosphorylation of p53 at Ser ${ }^{392}$ appeared earlier and higher than MCF-7 cells. Thus, the different responses of $\mathrm{Ser}^{392}$ maybe due to varied sensitivity induced by HPV-16E6. It is reported that phosphorylation of p53 at $\operatorname{Ser}^{392}$ was an early response to a wide range of stress-inducing conditions. Ser ${ }^{392}$ is phosphorylated by the protein kinase CK2 after UV and ionizing radiation treatment $(35,36)$. It has been shown to enable the transcriptional activation of the $\mathrm{p} 53$ protein in vitro (37) and also seems to be important for p53-mediated transactivation in vivo $(38,39)$. Therefore, the phosphorylation of p53 at $\operatorname{Ser}^{15}, \operatorname{Ser}^{20}$, and $\operatorname{Ser}^{392}$ could stabilize and activate p53, which ultimately induces the irreversible cell cycle arrest and apoptosis in response of DNA damage stress. Since the sequential phosphorylation of p53 has a time-ordered manner, it was suspected that at least some of them are interdependent reflecting mechanisms which could permit signal amplification and the integration of information from diverse signaling pathways (34). Taken together, in the transient HPV-16E6 expressing system, we observed obvious phosphorylation of p53 at three sites, $\mathrm{Ser}^{15}, \mathrm{Ser}^{20}$, and $\mathrm{Ser}^{392}$ in wild-type p53 cell lines.

In summary, we observed HPV-16E6 phosphorylated p53 at multiple sites. The different phosphorylated p53 sites may perform different functions in the pathogenesis of HPV. Whether this is one of the mechanisms to anti-virus infection employed by the host cells, or whether the phosphorylated p53 contributes to carcinogenesis induced by high risk HPV-E6 deserve further research.

\section{References}

1. Zur Hausen H: Papillomaviruses in human cancer. Cancer 59: 1692-1696, 1987.

2. Zheng ZM and Baker CC: Papillomavirus genome structure, expression, and post-transcriptional regulation. Front Biosci 11: 2286-2302, 2006.

3. Kehmeier E, Rühl H, Voland B, Stöppler MC, et al: Cellular steady-state levels of 'high risk' but not 'low risk' human papillomavirus (HPV) E6 proteins are increased by inhibition of proteasome-dependent degradation independent of their p53and E6AP-binding capabilities. Virology 299: 72-87, 2002.

4. Lazo PA: The molecular genetics of cervical carcinoma. Br J Cancer 80: 2008-2018, 1999.

5. Hiraiwa A, Kiyono T, Segawa K, et al: Comparative study on E6 and E7 genes of some cutaneous and genital papillomaviruses of human origin for their ability to transform $3 \mathrm{Y} 1$ cells. Virology 192: 102-111, 1993.

6. Scheffner M, Werness BA, Huibregtse JM, et al: The E6 oncoprotein encoded by human papillomavirus types 16 and 18 promotes the degradation of $\mathrm{p53}$. Cell 63: 1129-1136, 1990.

7. Kawamata Y, Mitsuhashi A, Unno Y, Kado S, Shino Y, Uesugi K, Eguchi O, Ishii J, Seki K, Sekiya S and Shirasawa H: HPV 16E6-mediated degradation of intrinsic p53 is compensated by upregulation of p53 gene expression in normal cervical keratinocytes. Int J Oncol 21: 561-567, 2002.

8. Butz K, Shahabeddin L, Geisen C, Spitkovsky D, Ullmann A and Hoppe-Seyler F: Functional p53 protein in human papillomaviruspositive cancer cells. Oncogene 10: 927-936, 1995.

9. Yonezawa Y, Hada T, Uryu K, et al: Mechanism of cell cycle arrest and apoptosis induction by conjugated eicosapentaenoic acid, which is a mammalian DNA polymerase and topoisomerase inhibitor. Int J Oncol 30: 1197-1204, 2007.
10. Meek DW: The p53 response to DNA damage. DNA Repair 3: 1049-1056, 2004

11. Kanellou P, Zaravinos A, Spandidos DA, et al: Genomic instability, mutations and expression analysis of the tumour suppressor genes p14(ARF), p15(INK4b), p16(INK4a) and p53 in actinic keratosis. Cancer Lett 264: 145-161, 2008.

12. Giannakakou P, Nakano M, Nicolaou KC, et al: Enhanced microtubule-dependent trafficking and p53 nuclear accumulation by suppression of microtubule dynamics. Proc Natl Acad Sci USA 99: 10855-10860, 2002.

13. Rahman-Roblick R, Hellman U, Becker S, et al: Proteomic identification of p53-dependent protein phosphorylation. Oncogene 27: 4854-4859, 2008.

14. Carlisi D, Vassallo B, Lauricella M, et al: Histone deacetylase inhibitors induce in human hepatoma HepG2 cells acetylation of p53 and histones in correlation with apoptotic effects. Int J Oncol 32: 177-184, 2008.

15. Lavin MF and Gueven N: The complexity of p53 stabilization and activation. Cell Death Differ 13: 941-950, 2006.

16. Unger T, Sionov RV, Moallem E, Yee CL, Howley PM, Oren M and Haupt Y: Mutations in serines 15 and 20 of human p53 impair its apoptotic activity. Oncogene 18: 3205-3212, 1999.

17. Shieh SY, Ikeda M, Taya Y and Prives C: DNA damageinduced phosphorylation of p53 alleviates inhibition by MDM2. Cell 91: 325-334, 1997.

18. Sakaguchi K, Sakamoto H, Lewis MS, Anderson CW, Erickson JW, Appella E and Xie D: Phosphorylation of serine 392 stabilizes the tetramer formation of tumor suppressor protein p53. Biochemistry 36: 10117-10124, 1997.

19. Steegenga WT, van der Eb AJ and Jochemsen AG: How phosphorylation regulates the activity of p53. J Mol Biol 263: 103-113, 1996.

20. Siliciano JD, Canman CE, Taya Y, Sakaguchi K, Appella E and Kastan MB: DNA damage induces phosphorylation of the amino terminus of p53. Genes Dev 11: 3471-3481, 1997.

21. Chehab NH, Malikzay A, Stavridi ES and Halazonetis TD: Phosphorylation of Ser-20 mediates stabilization of human p53 in response to DNA damage. Proc Natl Acad Sci USA 96: 13777-13782, 1999.

22. Finlan LE, Nenutil R, Ibbotson SH, Vojtesek B and Hupp TR: CK2-site phosphorylation of p53 is induced in DeltaNp63 expressing basal stem cells in UVB irradiated human skin. Cell Cycle 5: 2489-2494, 2006.

23. Shin YC, Nakamura H, Liang X, Feng P, Chang H, Kowalik TF and Jung JU: Inhibition of the ATM/p53 signal transduction pathway by Kaposi's sarcoma-associated herpesvirus interferon regulatory factor 1. J Virol 80: 2257-2266, 2006.

24. Li L, Guo L, Tao Y, Zhou S, Wang Z, Luo W, Hu D, Li Z, Xiao L, Tang M, Yi W, Tsao SW and Cao Y: Latent membrane protein 1 of Epstein-Barr virus regulates p53 phosphorylation through MAP kinases. Cancer Lett 255: 219-231, 2007.

25. Granja AG, Nogal ML, Hurtado C, Salas J, Salas ML, Carrascosa AL and Revilla Y: Modulation of p53 cellular function and cell death by African swine fever virus. J Virol 78: 7165-7174, 2004.

26. Li X and Coffino P: High-Risk human papillomavirus E6 protein has two distinct binding sites within p53, of which only one determines degradation. J Virol 70: 4509-4516, 1996.

27. Cinti C, Claudio PP, Luca AD, Cuccurese M, Howard CM, D'Esposito M, Paggi MG, Sala DL, Azzoni L, Halazonetis TD, Giordano A and Maraldi NM: A serine 37 mutation associated with two missense mutations at highly conserved regions of p53 affect pro-apoptotic genes expression in a T-lymphoblastoid drug resistant cell line. Oncogene 19: 5098-5105, 2000.

28. Damia G, Filiberti L, Vikhanskaya F, Carrassa L, Taya Y, D'incalci $\mathrm{M}$ and Broggini $\mathrm{M}$ : Cisplatinum and taxol induce different patterns of p53 phosphorylation. Neoplasia 3: 10-16, 2001.

29. Das KC and Dashnamoorthy R: Hyperoxia activates the ATRChk1 pathway and phosphorylates p53 at multiple sites. Am J Physiol Lung Cell Mol Physiol 286: L87-L97, 2004.

30. Hiramatsu K, Ogino T, Ozaki M and Okada S: Monochloramine inhibits ultraviolet $\mathrm{B}$-induced p53 activation and DNA repair response in human fibroblasts. Biochim Biophys Acta 1763: 188-196, 2006.

31. Chen Y, Miao ZH, Zhao WM and Ding J: The p53 pathway is synergized by p38 MAPK signaling to mediate 11,11'-dideoxyverticillin-induced G2/M arrest. FEBS Lett 579: 3683-3690, 2005 . 
32. Pabla N, Huang S, Mi QS, Daniel R and Dong Z: ATR-Chk2 signaling in p53 activation and DNA damage response during cisplatin-induced apoptosis. J Biol Chem 283: 6572-6583, 2008.

33. Craig AL, Burch L, Vojtesek B, Mikutowska J, Thompson A and Hupp TR: Novel phosphorylation sites of human tumour suppressor protein p53 at Ser20 and Thr 18 that disrupt the binding of $\mathrm{mdm} 2$ (mouse double minute 2) protein are modified in human cancers. Biochem J 342: 133-141, 1999.

34. Saito S, Yamaguchi H, Higashimoto Y, Chao C, Xu Y, Fornace AJ Jr, Appella E and Anderson CW: Phosphorylation site interdependence of human p53 post-translational modifications in response to stress. J Biol Chem 278: 37536-37544, 2003.

35. Sayed M, Pelech S, Wong C, Marotta A and Salh B: Protein kinase CK2 is involved in G2 arrest and apoptosis following spindle damage in epithelial cells. Oncogene 20: 6994-7005, 2001
36. Blaydes JP and Hupp TR: DNA damage triggers DRB-resistant phosphorylation of human p53 at the CK2 site. Oncogene 17: 1045-1052, 1998

37. Hupp TR and Lane DP:Two distinct signaling pathways activate the latent DNA binding function of p53 in a casein kinase IIindependent manner. J Biol Chem 270: 18165-18174, 1995.

38. Wallace M, Coates PJ, Wright EG and Ball KL: Differential posttranslational modification of the tumour suppressor proteins $\mathrm{Rb}$ and p53 modulate the rates of radiation-induced apoptosis in vivo. Oncogene 20: 3597-3608, 2001.

39. Hao M, Lowy AM, Kapoor M, Deffie A, Liu G and Lozano G: Mutation of phosphoserine 389 affects p53 function in vivo. J Biol Chem 271: 29380-29385, 1996. 